\title{
Guiding principles for natural product drug discovery
}

David Camp ${ }^{1, *}$ Rohan A. Davis, ${ }^{1}$ Elizabeth A. Evans-Illidge ${ }^{2}$ and Ronald J. Quinn ${ }^{1}$

${ }^{1}$ Eskitis Institute, Griffith University, Brisbane, Queensland 4111, Australia

${ }^{2}$ Australian Institute of Marine Science, Townsville, Queensland, 4810, Australia 
Abstract. Natural products (NPs) have historically been a fertile source of new drugs for the pharmaceutical industry. However, this once popular approach has waned considerably over the past two decades as the high-throughput screening (HTS) of mega-libraries comprised mainly of molecules with non-natural (synthetic) motifs has unfolded. Contemporary HTS libraries contain molecules compliant with physicochemical profiles considered essential for downstream development. Until recently, there was no strategy that aligned NP screening with the same physicochemical profiles. An approach based on Log $\mathrm{P}$ has addressed these concerns and, together with advances in isolation, afforded NP leads in timelines compatible with pure compound screening. Concomitant progress related to access of biological resources has provided long-awaited legal certainty to further facilitate NP drug discovery.

\section{Key terms}

Convention on Biological Diversity (CBD): an international treaty that addresses environmental and biodiversity conservation as well as associated trade, development and intellectual property rights. It was opened for signature in 1992 and entered into force in 1993. The CBD has three objectives: the conservation of biodiversity, the sustainable use of its components, and the equitable sharing of benefits arising from the use of genetic resources.

Nagoya Protocol: a legally binding protocol to the CBD. It provides further specific and legally enforceable instruction on the practical application and implementation of provisions pertaining to access and benefit sharing and the use of traditional knowledge. The Nagoya Protocol is expected to be ratified in 2012. 
Biodiscovery: the search for products and processes derived from biodiversity and inherent biochemical systems which can be developed into new applications in a range of industry sectors that includes pharmaceuticals and agrichemicals. The term biodiscovery is preferred to bioprospecting, to avoid connotations of unsustainable exploitation of resources and to better capture the nature of research and discovery.

Chemistry space: many different descriptors are used to represent molecules in silico [1]. Descriptors, inter alia, can be used to describe molecular and physicochemical properties (e.g. molecular weight, rotatable bonds, water solubility, etc.), or be calculated from a molecule's topology to describe properties like polar surface area. Chemistry space is a term that is often used in place of "multi-dimensional descriptor space" [2] and, conceptually, is the space occupied by all energetically stable stoichiometric combinations of electrons, atomic nuclei and topologies in discrete molecules [3]. Drug-like chemistry space is defined here by a particular set of descriptors that limits total chemistry space to carbon-based small molecules that share certain characteristics with other molecules that act as drugs. The number of drug-like molecules has been estimated to lie between $10^{18}-10^{200}$ compounds [1].

$\log$ P: defined as the ratio of the non-ionized form of a drug that is distributed between $n$-octanol and water phases at equilibrium. Higher values are indicative of greater lipophilicity.

PAINS: literally pan-asssay interfering compounds $[4,5]$; these are frequent hitters or otherwise promiscuous compounds containing substructures that often escape in silico filters designed to identify reactive functional groups in small molecules. Because PAINS can also contain protein-reactive substructures, molecules with such moieties typically display a trend of nonspecific biological activity as data from more assays are analyzed. 
Prefractionated library: a generic term that is typically used to describe any fractionation of crude extracts before primary screening. Prefractionation of crude extracts into fractions containing a few to many components is achieved by column chromatography, high-performance liquid chromatography (HPLC), or liquid-liquid partitioning. The simplest prefractionation protocols can reduce a crude extract to one fraction (e.g. the enrichment of alkaloids in a sample using cation exchange) while more involved procedures have been reported to afford up to 200 fractions per crude extract.

Mass-directed isolation: the process of isolating compounds from some type of biota (e.g., marine invertebrates, plants, microbes, etc.) that is based solely on mass spectrometric (MS) data. In relation to biodiscovery, this involves the initial identification of MS ions in a bioactive extract or fraction that is predicted to correspond to the active compound(s). Compounds are isolated following large-scale extraction of biota by chromatography and MS analysis of the fractions. Biological evaluation is then undertaken to confirm activity and potency.

Bioassay-guided fractionation: the process of isolating biologically active compounds from some type of biota (e.g. marine invertebrates, plants, microbes, etc.) that is based solely on bioactivity. Biological screening initially identifies a bioactive extract or fraction from a NP-based library. Large-scale extraction of the relevant biota is then undertaken, followed by iterative rounds of chromatography withd biological testing conducted after each fractionation step. Only those fractions showing bioactivity undergo subsequent separation, and this is a process requiring many cycles until the compound(s) responsible for initial screening activity are isolated.

Dereplication: the process by which the chemical and biological characteristics of the unknown compounds are compared with the chemical and biological characteristics of known compounds from databases to eliminate those that have been identified 
previously. Some NPs are discovered more frequently than others during screening programs. As the number of described NPs increases, so does the probability of rediscovering known compounds.

About $34 \%$ of current marketed drugs can trace their origins back to an unmodified natural product (NP) or a semi-synthetic analogue [6]. While this metric reflects the historic role NPs have played in the pharmaceutical industry, it does not capture the reality that this once popular approach has waned considerably since the early 1980s. The decline can be traced back to a paradigm shift that coalesced advances in molecular biology, combinatorial chemistry and high-throughput screening (HTS). It was expected that combinatorial chemistry would deliver massive numbers of novel chemical motifs that would ultimately result in the filing of increasing numbers of new chemical entities (NCEs). At the same time biodiverse collections became harder to legally acquire and use for commercial research due to lack of certainty and clarity over access and benefit sharing (ABS) requirements [7,8].

The synergies between these new technologies, and the changing landscape for biodiscovery, led many pharmaceutical companies to either cut back or disband their NP drug discovery programs and shift resources into the new paradigm. The situation worsened for NP extract screening as the speed of discovery became de rigor, although this later morphed into the "fail fast, fail cheap" mantra, as combinatorial libraries did not live up to the high expectations placed on them.

To maintain the forward momentum of projects performed in industry that utilized both pure compound library and NP extract screening, hits from pure compound libraries were often progressed to lead identification (hit-to-lead) in 6 months while it took 1-2 full-time employees (FTE) in this time frame to complete a reasonable number 
of bioassay-guided fractionations (e.g. 20) to arrive at the hit stage. The concomitant prosecution of both pure compound and extract screening highlighted several shortcomings of bioassay-guided fractionation when this modus operandi was simply translated to the new paradigm.

First, the screening group had to maintain cells or a quantity of protein for the NP group that delivered fewer and fewer fractions as the active component(s) were gradually purified. This is wasteful in terms of reagents being added to empty wells of microtiter plates and also in terms of time that screening staff could use to focus on a new assay. Second, structural elucidation of the actives was required following an often laborious isolation which could add to the frustration, particularly if the molecule violated most, if not all, lead- and drug-like physicochemical properties, or contained a substructure that was a medicinal chemistry "dead end". Third, if project reviews are carried out after 6 months, a not unreasonable period following initial screening then, more often than not, the same amount of data is not available for all isolations. Fourth, acquisition of secondary and counter screening data during hit identification, and early pharmacokinetic data for the hit-to-lead phase, potentially means that recollection of the original biota (microbial biota can be re-cultured) may be necessary so that the active component could be reisolated in larger quantities unless the molecule was synthetically tractable (and medicinal chemistry resources were available to attempt a synthesis).

As a result, NP drug discovery was increasingly marginalized and viewed as a last resort by project teams; only to be considered when screening the compound library did not yield any leads. Put simply, classical bioassay-guided fractionation so engrained in NP drug discovery was not competitive with the HTS timelines of pure compound libraries. Consequently, the quest for NP drug discovery over the past 20 years has been increasingly taken up by smaller niche companies offering a point of difference and the 
"true believers" from publicly funded research organisations, like the National Cancer Institute (U.S.A.), and various academic groups.

Yet, despite this somewhat melancholy backdrop, a recent review by Newman and Cragg has shown that NPs and their derivatives continue to make a significant contribution to the pharmaceutical industry [6]. Thus, from 1981-1987, NPs contributed substantially to the total number and percentage of all new drug approvals per annum. After this, though, the number of drug approvals based on NPs and their semi-synthetic analogues began to drift downwards. To some extent, however, NPs are a microcosm of the pharmaceutical industry and the decreasing number of approvals each year is merely reflecting a general trend. Fortunately, the value of NPs is captured when analyzed as a percentage of all new drug approvals (notwithstanding the fact this metric resembles the fluctuations in the stock market). Hence, after a somewhat steady period between 19811986, a definite decline is observed from 1987-1991 where the percentage of new approvals drops to $20 \%$. This is followed by a short rally over the next 3 years where the average jumps to $40 \%$ before a crash occurs in 1995 (29\%) which turns into a definite bear market that reaches a nadir of $12.2 \%$ in 1997. A bullish, though somewhat erratic, run has since played out reaching a peak in 2010 where NPs and their derivatives accounted for $50 \%$ of all new drug approvals. Clearly, NPs are still furnishing leads to the pharmaceutical industry, albeit in lower total numbers than pre1987. The challenge, as we see it, is to better integrate NPs into contemporary drug discovery so that both the total number and percentage contributions can increase.

\section{Guiding principles for natural product drug discovery}

To achieve this goal, we believe that there are two broad principles that together can underpin the discovery of NP drugs. Further development/refinement of these 
principles over time will not only deliver better leads for the pharmaceutical industry but will also make the screening of NP libraries more competitive and truly complementary to pure compound libraries.

Perhaps the easiest of these guiding principles to implement is to simply learn from the mistakes that initially plagued the combinatorial chemistry paradigm and develop NP workstreams that: 1) address physicochemical profiling prior to screening and; 2) make better use of technology to constantly shorten discovery timelines.

It should be noted that the early period of the combinatorial chemistry paradigm was not without controversy [9]. The focus on quantity and speed unfortunately meant that combinatorial chemistry and HTS was oversold as a panacea for the dearth of NCEs. When NCEs did not emerge from the pipeline, the focus rightly shifted away from throughput and towards quality. The readjustment was driven, in part, by a better understanding of the types of molecules that should be screened and the end point that resulted in a drug $[10,11]$.

Lipinski et al.'s seminal analysis revealed that many combinatorial libraries contained molecules that did not echo specific physicochemical properties common to $90 \%$ of orally active drugs that advanced to phase II clinical trials. This disconnect led the authors to summarize their findings via the now well-known "Rule of 5" (Ro5) [12], so-called because the first four parameters are all multiples of five. In essence, the Ro5 is a set of guidelines that articulates the ranges of four key properties assumed to be a good indicator of oral absorption, i.e., MW < 500; calculated $\log \mathrm{P}(\mathrm{cLog} \mathrm{P})<5$; number of H-bond donors $(\mathrm{HBD})<5$; and number of H-bond acceptors $(\mathrm{HBA})<10$. In this sense, the Ro5 does not define drug-like chemical space per se but is rather a predictor for oral bioavailability [13]. Potential bioavailability issues occur if there are two or more Ro5 violations. 
It is politic to remember that the Ro5 also contains an important caveat, the so called $5^{\text {th }}$ rule; namely "compound classes that are substrates for biological transporters are exceptions to the rule" [12]. "Pleading the $5^{\text {th" }}$ has been used by proponents of NPs to justify the inclusion of what many in the pharmaceutical industry may consider to be dubious molecules into screening libraries. While we would support the inclusion of NPs into screening sets, we would also argue that it should be for the right reasons and not because their pedigree automatically affords them some special status under the " $5^{\text {th }}$ amendment". For example, some more structurally complex NPs like paclitaxel $\left(\right.$ Taxol $\left.^{\circledR}\right) \mathbf{1}$ or rapamycin $\left(\right.$ Rapamune $\left.^{\circledR}\right) \mathbf{2}$, most likely take full advantage of their molecular architecture and spatial arrangement of functional groups, rather than an active transport mechanism, to make a mockery of the Ro5 $[14,15]$. Thus, it is not the fact they are NPs automatically captured by the $5^{\text {th }}$ rule that makes them and other structurally complex NPs like trabectedin (Yondelis ${ }^{\circledR}$ ) $\mathbf{3}$ good drugs existing outside of "Lipinski space", but some of their other features/properties. The real issue is to understand what these are and adjust a NP drug discovery program accordingly.

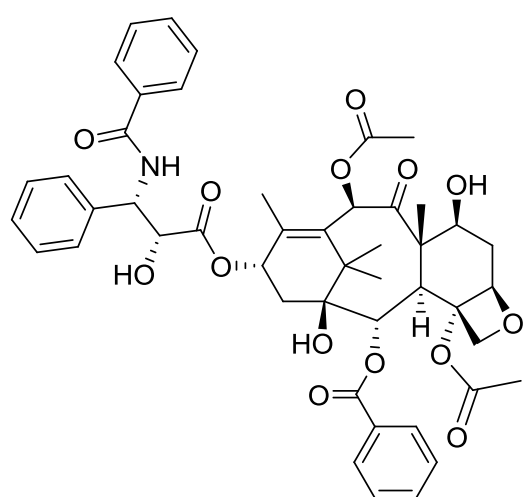

1

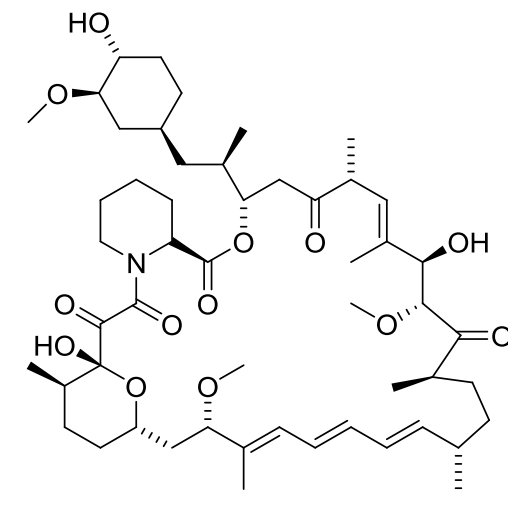

2

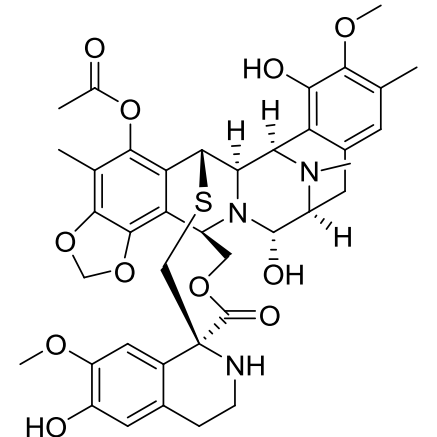

3

Figure 1. Chemical structures for paclitaxel $\left(\operatorname{Taxol}^{\circledR}\right)$ 1, rapamycin $\left(\right.$ Rapamune $\left.^{\circledR}\right)$ 2, and trabectedin (Yondelis ${ }^{\circledR}$ ) 3. 
In this respect, while Lipinski’s pivotal investigation was important in guiding the process toward the end point for orally available drugs, it was another two years before direction concerning the physicochemical profiles of molecules that comprised the actual screening set (i.e. chemical starting points for drug discovery) was reported by Teague and co-workers [16]. "Lead-like" molecules are smaller and more polar than drug-like molecules and were proposed to address the generally observed trend within the pharmaceutical industry that the initial hit from HTS tends to increase in mass as chemical moieties are introduced to improve selectivity, potency, and bioavailability (or any combination thereof). For this reason it makes sense to start below the drug-like profile so that additional mass and functionality can be added en route to the NCE without it potentially suffering from "molecular obesity" [13].

Exactly how far below the drug-like profile a chemical starting point should reside is open to interpretation (Table 1). Oprea et al., for example, defined a lead-like molecule employing a property-based analysis [17]. However, Hann and Oprea also advocated screening libraries of molecules with "reduced complexity" that had even more stringent physicochemical profiles than lead-like molecules [18]. Significantly, although the actual guidelines being implemented may differ, the physicochemical profiling of compound libraries that now occurs in the pharmaceutical industry has become an intrinsic part of the design and selection process. 
Table 1. Physicochemical profiles for reduced complexity, lead-like and drug-like molecules.

\begin{tabular}{|c|c|c|c|}
\hline $\begin{array}{l}\text { Physicochemical } \\
\text { parameter }\end{array}$ & $\begin{array}{l}\text { Reduced } \\
\text { complexity }\end{array}$ & Lead-like & Drug-like \\
\hline molecular weight & $\leq 350$ & $\leq 460$ & $\leq 500$ \\
\hline H-bond donors & $\leq 3$ & $\leq 5$ & $\leq 5$ \\
\hline H-bond acceptors & $\leq 8$ & $\leq 9$ & $\leq 10$ \\
\hline cLog P & $\leq 2.2$ & $-4.6-4.2$ & $\leq 5$ \\
\hline rotatable bonds & $\leq 6$ & $\leq 10$ & - \\
\hline heavy atoms & $\leq 22$ & - & - \\
\hline number of rings & - & $\leq 4$ & - \\
\hline $\log S_{w}{ }^{a}$ & - & $\geq-5$ & - \\
\hline
\end{tabular}

${ }^{\mathrm{a}} \mathrm{Log}$ of water solubility

A short time after the concepts of lead- and drug-likeness had gained traction, Leeson and Davis critically examined a wider range of physicochemical properties to determine which may actually be the most important for drug development [10]. Their hypothesis that the physicochemical parameters that remained consistent over the relatively short history of modern drug development were more likely to also be the most important was simple yet profound. A comparison of the physicochemical properties of 864 drug approvals up to 1982, and 329 between 1983-2002, showed that the median cLog $\mathrm{P}$, per cent polar surface area (\% PSA) and the number of HBDs remained the same while other physicochemical properties like MW, HBA, rotatable bonds and the number of rings increased in a statistically significant manner [10]. Of the three most constant physicochemical properties, lipophilicity, as measured by cLog $\mathrm{P}$, was found to vary the least prompting Leeson to rate it as the most important [10]. 
This was not completely unexpected as the role of Log P in influencing drug potency, pharmacokinetics and toxicity had been established for many years [19-22] and has even prompted Ganesan to dub it the "Lord of the Rules" for drug discovery and development [23].

The second guiding principle is somewhat more ethereal in the sense that its execution is not generally able to be carried out by those involved in the science, but rather by high level policy makers from national governments. However, given the Convention on Biological Diversity (CBD) has fundamentally changed biodiscovery, it is absolutely essential that anyone contemplating NP drug discovery stays abreast of any developments and remains cognisant of emerging national and international legislation that permits ABS of genetic resources.

Clearly, NP drug discovery would not be possible without access to the world's biodiversity of which greater than $80 \%$ of terrestrial biodiversity is estimated to be spread across a mere 17 countries [24]. The distribution of the world's genetic resources is important as, historically, biodiversity has been approximately inversely proportional to a country's wealth and scientific capacity to not only undertake biodiscovery, but also commercialize outcomes [25]. A dichotomous paradigm has ensued whereby the developing world became a supplier of biodiversity (and sometimes associated traditional knowledge) that the developed world translated into commercial outcomes [26]. By the late 1980s many of the governments of developing countries and nongovernment organizations effectively lobbied that the situation was inequitable [27-29]. Interestingly, the global shift from NPs to combinatorial chemistry as a source of molecular diversity for screening programs coincided with the advent of the term “biopiracy” during the 1980s. 
The disconnect between the wealth of genetic resources in the majority of megadiverse countries and their ability to translate this into a commercial outcome was central to international negotiations that resulted in a new treaty - the CBD - which was opened for signature at the first Earth Summit in Rio de Janeiro in 1992, and entered into force in 1993. The CBD has three clear objectives: the conservation of biodiversity, the sustainable use of its components, and the equitable sharing of benefits arising from the use of genetic resources [101]. In this respect the CBD is much more than an environmental treaty to address the alarming rate of global biodiversity loss; it is a hybrid that also deals with trade, development, and intellectual property rights [30].

How these two guiding principles have been addressed by research groups from academia and industry to improve the underlying process, and by international law makers in creating the opportunity in the first place, will be discussed in more detail in their respective sections below.

\section{Guiding principle 1: Addressing physicochemical properties in natural product screening and improving the speed that hits, leads and drugs are isolated.}

\section{Screening of pure natural product libraries}

There have been several approaches to address the deficiencies associated with screening NP extracts in an effort to facilitate downstream isolation of active components. One has entailed isolation and structural elucidation of as many pure NPs as possible [31-33]. This strategy has several obvious advantages as the isolated compounds can be treated the same as any other compound in a library allowing immediate assessment of the compound's potential thus eliminating the time delay between identification of a hit extract and isolation of the active NP. With a structure in- 
hand, it is also possible to exclude compounds from the screening set that do not conform to prescribed physicochemical parameters or have chemical alerts associated with substructures.

Unfortunately, it is simply not yet feasible to isolate every minor component in an extract library due to the underlying logistics, cost and technology deficit. Consequently, the limited throughput associated with purification restricts the ability to build a library representative of all NP chemical space. Ignoring minor components would lead to an inevitable loss of chemical diversity. As a result, approaches based on pure NPs alone are neither comprehensive nor generic, particularly if a biased subset (e.g. alkaloids) is being pursued.

By way of example, it has previously been demonstrated that it is possible to prepare a screening library of highly diverse NPs that are drug-like in their physicochemical parameters [33]. However, this is still a limited subset of all NP diversity and fails to deliver a comprehensive coverage of NP chemical space. A more complete exposure of NPs can only be achieved via a comprehensive sampling of the chemical diversity found in nature through inclusion of minor components found in extracts using HTS.

\section{Screening crude extract libraries}

Compound diversity is greatest in crude extracts and, as a consequence, their screening addresses the issue of minor components that may not be isolated using the pure NP strategy. Crude extract libraries dovetail nicely with HTS and, indeed, were reported as the progenitors of pure compound screening in Pfizer [34]. We also note that we performed our first HTS on crude extract libraries in a collaboration with Astra in 1994 [35,36]. In addition to their high chemical diversity, crude extracts can be 
prepared quickly and inexpensively (like combinatorial chemistry libraries). However, crude extracts also have several drawbacks. It has been reported that the chemical complexity of crude extracts can lead to minor metabolites being undetected [37], particularly if they are masked by other components or if NP pan assay interfering compounds (PAINS) [4,5] are present. Generally speaking, the presence of NP PAINS like large polyphenolic tannins are notorious for interfering with many assay formats and screening technologies [38-40] and can result in a significant number of false positives that may be time consuming to dereplicate. Ideally, NP PAINS would be removed from an extract prior to screening so that detection of potentially potent minor components is facilitated.

Furthermore, the isolation of the active component can be time- and resourceintensive, and can result in chemically unattractive compounds being frequently isolated. Despite an attractive veneer, the HTS of crude extract libraries does not adequately address the issues of isolating lead- or drug-like molecules in a timely manner.

\section{Screening prefractionated extract libraries}

Numerous prefractionation strategies have been developed to address issues associated with the HTS of crude extracts in an effort to maintain and detect minor components, improve the quality of screening data and reduce timelines associated with downstream bioassay-guided fractionation. Approaches are broadly scoped with reports ranging from the preparation of 4-200 fractions per sample. Table 2 summarizes published strategies for the preparation of prefractionated HTS-ready libraries. 


\begin{tabular}{|c|c|c|c|c|c|c|c|}
\hline Group & Year & Sample origin & $\begin{array}{l}\text { Pretreatment } \\
\text { strategy }\end{array}$ & $\begin{array}{l}\text { No. pretreated } \\
\text { extracts }\end{array}$ & $\begin{array}{l}\text { No. fractions per } \\
\text { pretreated extract }\end{array}$ & $\begin{array}{l}\text { No. HPLC fractions } \\
\text { per sample }\end{array}$ & Plate format \\
\hline Sequoia Sciences [38] & 2002 & plant & $\begin{array}{l}\text { Silica } \\
\text { PAG }\end{array}$ & $6^{b}$ & 40 & 200 & $96 / 384$ \\
\hline bioLeads GmbH [32] & 2002 & microbial & not specified & 2 & varied (1-8) & $10^{\mathrm{c}}$ & not specified \\
\hline Merlion [39] & 2007 & microbial & none & none & none & $4^{\mathrm{a}, \mathrm{d}}$ & 96 \\
\hline University of Utah $^{\mathrm{e}}[41]$ & 2008 & marine inv. & HP20SS & $5^{\mathrm{f}}$ & 20 & 80 & 96 \\
\hline Wyeth [37] & 2008 & microbial $^{\mathrm{g}}$ & HP20/XAD7 & 1 & 10 & 10 & 96 \\
\hline $\begin{array}{l}\text { St Jude Children's } \\
\text { Research Hospital }^{\text {e }}[40]\end{array}$ & 2010 & plant & PAG & 1 & 24 & 24 & 384 \\
\hline Griffith University [42] & 2012 & $\begin{array}{l}\text { plant } \\
\text { marine inv. }\end{array}$ & $\begin{array}{l}\text { PAG }^{\mathrm{h}} \\
\text { Oasis HLB }\end{array}$ & 1 & 11 & 11 & 384 \\
\hline
\end{tabular}

4 a. Performed on $\mathrm{C}_{18}$ HPLC except for bioLeads where details were not specified

5 b. Six extracts originally ( 5 organic and 1 aqueous); hexane rich extract discarded

6 c. Nine fractions from the culture, 1 fraction from the mycelia

7 d. Crude extract went straight to HPLC where six fractions were obtained; the first (solvent front) and final fractions were discarded

8 e. Organization of corresponding author provided in cases where two or more groups contributed to the publication

9 f. Five extracts originally (4 organic and 1 aqueous); aqueous extract discarded

10 g. Crude extracts from at least 2 cultures were pooled prior to pretreatment

11 h. PAG used on plant samples only 
13 It is interesting to note that MerLion and Wyeth developed similar reversed-phase

$14 \mathrm{C}_{18}$ high-performance liquid chromatography (HPLC) methods to address the HTS of

15 extracts derived from microbial samples [37,39]. Importantly, the downstream HTS

16 data reported by both groups vindicates their decision to screen prefractionated libraries

17 compared with crude extracts. In each case, around $80 \%$ of the activity was found only

18 in the fractions; the crude extract accounted for approximately $10 \%$ of the total activity $19[37,39]$.

20 All groups that worked with plant samples employed polyamide gel (PAG) solid 21 phase extraction (SPE) to remove tannins [38,40,42]. While marine invertebrates do not 22 contain tannins, they can have a high salt content which may dilute compounds of 23 interest and reduce the likelihood of detection. Salts can also suppress ionization in 24 downstream liquid chromatography-mass spectrometry (LC-MS) analysis making identification of the active component more challenging [41]. Salts have effectively been removed from marine invertebrates via SPE through a HP-20SS (polystyrene) adsorbent [41] or by employing a prewash on a HPLC column [42] just prior to fraction collection.

Examples of automated prefractionation following extract screening have also been reported. A recent example by Crews et al. has outlined how HTS of (mainly)

31 crude extracts derived from marine invertebrates, plants and microbial specimens can be 32 prosecuted [43]. Salts and lipophilic compounds were ostensibly removed from the 33 marine organisms via water and hexane extractions, respectively, while tannins from 34 plant samples were excluded by PAG. After screening the ensuing library, hit extracts were subjected to an automated purification and fractionation process that was followed by dereplication and structure elucidation of the active components. However, the data 
37 from Merlion and Wyeth (obtained from 11 and 9 HTS campaigns, respectively) plainly

38 showed that hit rates were higher when fractions were screened compared with crude 39 extracts and suggests that screening a prefractionated library would be more efficient.

40 Indeed, lipophilic false positives like hexylcinnamaldehyde (cLog $\mathrm{P} \sim 5$ ) were isolated 41 using this process [43]. Detergent-like compounds and fatty acids/lipids are known to 42 form aggregates and interfere in certain HTS assays $[44,45]$. The presence of high Log 43 P components in the screening library is due to the fact that crude extracts invariably 44 contain lipophilic material unless some attempt is made to remove them. Moreover, 45 hexane extraction does not remove all lipophilic molecules [42]. Ultimately, screening 46 libraries based on crude extracts will be compromised in some way by the presence of 47 interfering high $\log \mathrm{P}$ constituents. Intriguingly, the screening of hexane extracts 48 (which potentially exacerbates the issues associated with crude extracts containing 49 lipophilic material) was also reported [43]. In one particular example described by the 50 authors at length, a common diterpene found in sponges, i.e. spongia-13(16),14-dien51 19-oic acid (cLog $\mathrm{P}=6.2)$, was isolated. The prefractionated approaches listed in Table 2 all attempt to eliminate interfering, nuisance and spectator compounds that have deleterious effects on an assay, are frequent hitters, or generally dilute potential molecules of real interest. But what molecules should be retained when viewed through the lens of drug discovery?

56 Recalling Lipinski's Ro5, Teague's original lead-like concept, Oprea's reduced 57 complexity sets, Leeson's analysis of the most important physicochemical properties, and that Log P is considered "Lord of the Rules"- all of which were developed in response to issues that originally troubled HTS of combinatorial chemistry libraries - it

60 follows that construction of a NP screening library, not only devoid of NP PAINS, but 61 also compliant with established lead- and drug-like parameters, particularly Log P, will 
62 enrich extracts (and subsequent fractions) with compounds that have a much higher

63 probability of progressing from hits to leads. Clearly, front-loading the screening set

64 will obviate the necessity to "build-in" functionality that accomplishes a more lead- or

65 drug-like profile at later lead identification/optimization stages.

66 Having said this, we do add what we consider to be an important caveat, namely,

67 the definition of a lead in NP drug discovery should be modified to account for large

68 MW compounds that can potentially fail up to three Ro5 parameters, i.e. MW, HBD and

69 HBA, but nevertheless satisfy the most important property, Log P. This captures leads

70 such as paclitaxel $\mathbf{1}$, rapamycin $\mathbf{2}$ and trabectedin $\mathbf{3}$, which were ultimately drugs in

71 their own right (Figure 1). This would also include molecules that required only minor

72 modification such as such as pneumocandin $\mathrm{B}_{0} 4$, which was converted to the antifungal

73 caspofungin $\left(\right.$ Cancidas $^{\circledR}$ ) 5 (Figure 2). Likewise, we would also contend that NPs

74 compliant with lead- or drug-like profiles, but nevertheless containing unattractive

75 structural features such as the five contiguous rings in camptothecin $\mathbf{6}$, that ultimately

76 afforded topotecan $\left(\right.$ Hycamtin $\left.^{\circledR}\right) 7$ and irinotecan $\left(\right.$ Camptosar $\left.{ }^{\circledR}\right)$ 8, should not

77 immediately be discounted by the cognitive bias of medicinal chemists. 

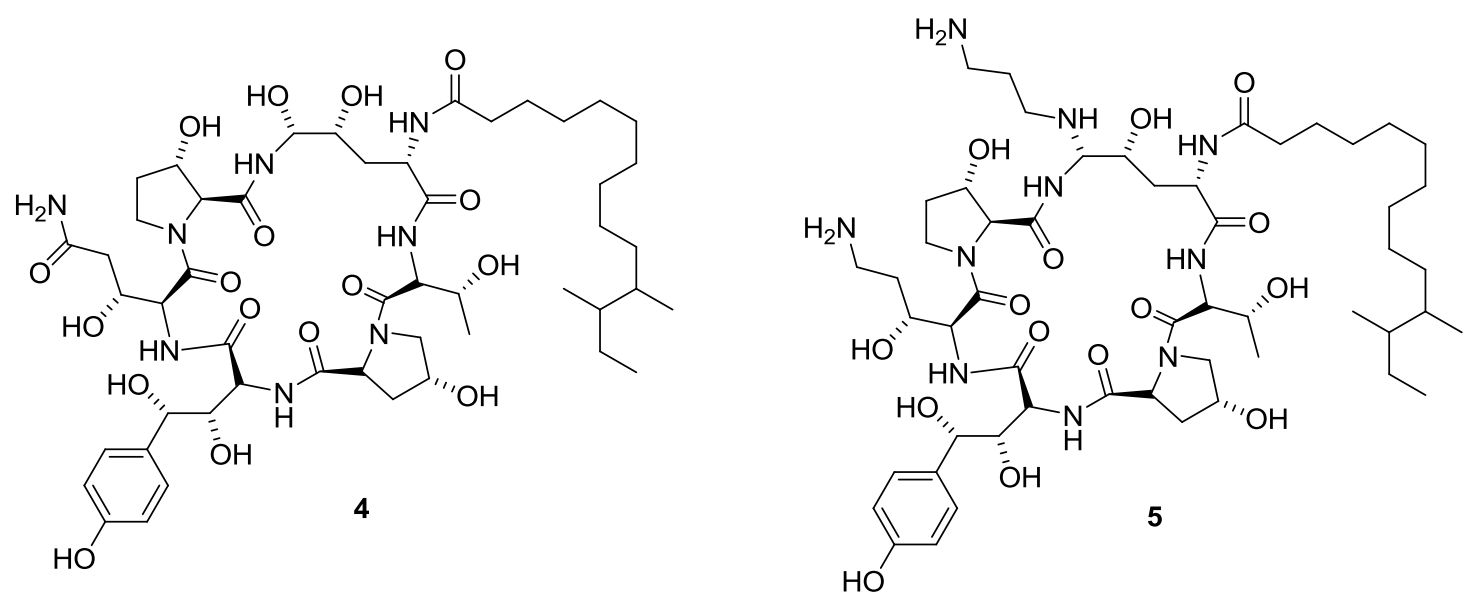

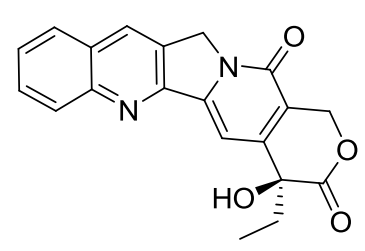

6<smiles>CC[C@]1(O)C(=O)OCc2c1cc1n(c2=O)Cc2cc3c(CN(C)C)c(O)ccc3nc2-1</smiles>

7

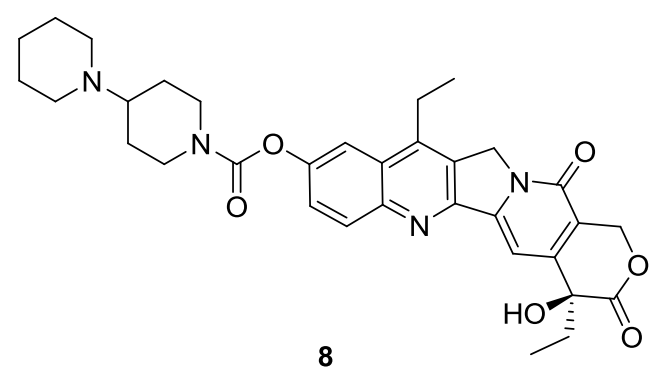

8

80 Figure 2. Chemical structures for pneumocandin $B_{0} \mathbf{4}$, caspofungin $\left(\right.$ Cancidas $\left.^{\circledR}\right) \mathbf{5}$, camptothecin 6, topotecan $\left(\right.$ Hycamtin $\left.^{\circledR}\right) 7$ and irinotecan $\left(\right.$ Camptosar $\left.{ }^{\circledR}\right) \mathbf{8 .}$ Returning to the issue of delivering NP leads compliant with lead- and drug-like physicochemical properties in a timely manner; there are two critical issues related to the NP drug discovery workstream that must be addressed before efficiency gains and improved outcomes are forthcoming. First, the screening set should be front-loaded

87 with components having lead- and/or drug-like physicochemical profiles. The profound and positive impact of physicochemical profiling is now reflected in libraries comprised of more lead- and drug-like compounds that, in turn, has translated into more leads from

90 second generation libraries progressing to the clinic [46,47]. We consider the screening 91 of NP libraries that employ similar physicochemical filtering to be absolutely essential 92 if NPs leads are to be taken up in a more widespread manner by industry once again. 
Even though the structure (and by logical extension, the concentration) of the individual components in a microtiter plate well containing a NP extract or fraction are generally not known before isolation is attempted, we would contend that an important goal of NP drug discovery is to afford new and novel leads. To our way of thinking, the structure is of secondary importance to ensuring the components are well positioned in lead- and drug-like chemical space in the context of screening extracts and prefractionated libraries. As a consequence, compounds that are isolated downstream from screening will intrinsically adhere to physicochemical profiles that will justify a potentially arduous isolation. Second, if NP drug discovery is to ever compete with timelines for the HTS of pure compounds, then the rate at which NPs are isolated requires vast improvement.

Next generation prefractionated extract libraries filtered on $\log P$

The correlation between lipophilicity and retention time on a $\mathrm{C}_{18}$ reversed phase HPLC column has been exploited to develop an alternative method to determine Log P

108 [48]. We have also observed a relationship between lipophilicity, as measured by a 109 compound's cLog $\mathrm{P}$, and retention time on a $\mathrm{C}_{18}$ reversed phase HPLC column while 110 undertaking bioassay-guided fractionation projects. Indeed, our earlier biodiscovery

111 efforts employing bioassay-guided fractionation following screening of 140,000 crude

112 extracts (35,000 macro biota extracted with 2 solvents and screened in duplicate) were 113 marred by pursuing late eluting, highly bioactive components that were ultimately

114 found to be useless as NP leads. Once this was realized, and understood in terms of 115 lead- and drug-like physicochemical properties, the process was modified accordingly

116 whereby the crude extracts were re-injected onto a reversed phase $\mathrm{C}_{18}$ HPLC column 117 and analyzed [49]. 
Over time, we recognized that molecules isolated from later eluting fractions consistently had both cLog $\mathrm{P}$ and $\log \mathrm{P}$ values $>5$ and, as a result, these fractions were excluded from further analysis. While the fractionation process was a step in the right

121 direction and helped steer isolation projects toward lead- and drug-like compounds that

122 addressed $\log \mathrm{P}$, it did not facilitate timely identification of actives. Clearly, a method

123 that pre-filtered extracts on Log $\mathrm{P}$ and allowed some preliminary structural data to be

124 obtained was required. Such a process would obviate the need to analyze extracts postscreening and concomitantly hasten the identification of potential hit compounds. toward developing a generic approach that could be applied to both major and minor constituents within crude or semi-purified extracts. Our current methodology [42] relies on initially preparing crude extracts that are subsequently passed through an SPE cartridge containing Oasis ${ }^{\circledR}$ HLB, which is a copolymer of divinylbenzene and $\mathrm{N}$ vinylpyrolidone. During exhaustive testing of adsorbents, we found that this particular matrix was superior in retaining high Log $\mathrm{P}$ components that, in the past, were present

133 in the screening set. The process effectively filters on $\log \mathrm{P}$ and allows the earlier

134 eluting components that may contain a highly desirable basic nitrogen atom to be captured. This observation also suggests that screening sets derived from Diaion ${ }^{\mathrm{TM}} \mathrm{HP}-$ 20SS [41] or from crude extracts, particularly hexanes, [43] would contain molecules with $\log \mathrm{P}>5$ that typically manifest as frequent hitters in biological assays. In a further refinement, based on Wyeth's [37] and Merlion's [39] reported HTS

139 data of their prefractionated libraries, we next aimed to concomitantly improve the 140 quality of screening data and increase the speed of isolation. Thus, the optimized 141 extracts were fractionated on reversed phase $\mathrm{C}_{18}$ HPLC to generate a prefractionated 142 library [42]. Eleven fractions were collected from 18,453 extracts to generate a 
143 screening set of 202,983 data points. The HPLC separation is significantly improved

144 following the removal of the highly lipophilic constituents in the previous step. Salts

145 from marine organisms are eliminated using a prewash on the HPLC column prior to

146 fractionation.

147 This methodology permits MW, structural data and retest of active pure

148 compounds to be acquired in a highly efficient manner directly following primary

149 screening, the point at which little to no chemical information is generally known about

150 bioactive constituents. Thus, confirmation is obtained by LC-MS analysis of the active

151 fraction to further resolve the individual constituents and obtain retention time,

152 ultraviolet (UV) spectra and, importantly, MW information for each component. In

153 some cases it is also possible to obtain preliminary structural data via nuclear magnetic

154 resonance (NMR) spectroscopy. Rescreening of the individual constituents allows the 155 precise compound(s) to be identified and affords some knowledge of potency and

156 novelty. The MS and NMR data can be used for dereplication and also as a trigger to

157 pursue an isolation project. This allows NP drugs that satisfy the Log P criteria, but

158 may fail other lead- and drug-like parameters, like Taxol ${ }^{\circledR} \mathbf{1}$, Rapamune ${ }^{\circledR} \mathbf{2}$ and

159 Yondelis ${ }^{\circledR} \mathbf{3}$, to still be isolated on the basis of potency, new/novel structural motifs or

160 ligand efficiency [50] if the supporting data warrants further effort.

161 The combined MW, HPLC and other spectroscopic data also facilitates scale-up

162 isolation of the active components without recourse to bioassay-guided fractionation.

163 Here, isolation of the actives from the original biota is guided by the chromatographic

164 retention time of the active in the prefractionated library. Ultimately, mass-directed

165 isolation can be used to home in on the desired molecule(s) in a highly efficient manner.

166 The first three HTS campaigns that used the prefractionated library were run

167 against malaria [51-54], human African trypanosomiasis (HAT) [55-58], and Yersinia 
168 outer protein E (YOPE) regulation [59]. Sixty compounds were isolated from the

169 malaria screen, 58 from HAT, and 30 from YOPE where activity ranged from good

$170 \quad\left(\mathrm{IC}_{50}<10 \mu \mathrm{M} ; 48\right.$ malaria, $\left.30 \mathrm{HAT}, 7 \mathrm{YOPE}\right)$ to moderate $\left(\mathrm{IC}_{50} 10-50 \mu \mathrm{M} ; 4\right.$ malaria,

$17110 \mathrm{HAT}, 10 \mathrm{YOPE}$ ) to poor ( $\mathrm{IC}_{50}>50 \mu \mathrm{M} ; 8$ malaria, $\left.18 \mathrm{HAT}, 13 \mathrm{YOPE}\right)$. Twenty-two

172 compounds resulting from these three HTS campaigns have been published, and their

173 chemical structures are shown in Figures 3-5. For the malaria and HAT projects, the

174 focus was on isolating compounds with $\log \mathrm{P}<5$ and $\mathrm{MW}<500$. Molecular weight

175 was not as critical as activity for the YOPE project and, as a consequence, bioactives

176 with higher MWs were isolated (Table 3). We have previously reported [42] that the

177118 compounds from the malaria and HAT projects were enriched in lead- and drug-

178 like profiles compared with the Dictionary of Natural Products [60]. In some cases, the

179 NP lead has progressed into lead identification and optimization projects. So far, 180 synthetic follow-up has been published for YOPE [61].

181 Interestingly, there were two compounds from the malaria project and seven 182 compounds from HAT that were not complaint with $\log \mathrm{P}<5$. Although the total 183 number of non-compliant molecules was small, the result was nevertheless puzzling 184 considering the process employed $\log \mathrm{P}$ as the primary filter. However, a more 185 thoughtful analysis would suggest that the presence of trifluoroacetic acid (a strong 186 acid) employed to filter on Log $\mathrm{P}$ would lead to ionization of NPs containing basic 187 moieties which, in turn, can lead to misleading results as Log P calculations specifically 188 predict the partitioning of neutral (i.e. un-ionized) species between $n$-octanol and water.

189 As a consequence, we believe that the distribution coefficient ( $\log D$ ) is a more 190 appropriate measure as it considers the distribution of both ionized and un-ionized 191 species at a given $\mathrm{pH}$. Indeed, it has been proposed that $\log \mathrm{D}$ at $\mathrm{pH} 5.5\left(\log \mathrm{D}_{5.5}\right)$, 192 which is the $\mathrm{pH}$ of the small intestine where oral drug absorption occurs, is a better 
193 description of the lipophilic nature of drug-like molecules under physiological

194 conditions [62]. Importantly, no compounds from the malaria project and only one

195 compound from the HAT project (unpublished structure) exceeded the cut-off value

196 when $\log \mathrm{D}_{5.5}>5$ was used to determine lipophilicity. Although the HAT-active

197 compound was found in the last fraction, this result could also indicate that the

198 algorithm used to determine $\log \mathrm{D}_{5.5}$ was not accurate for this class of compounds. The

199 only molecule in Table 3 that violates Log P (the HAT active compound 19) becomes

200 complaint when $\log \mathrm{D}_{5.5}$ is employed as a measure of lipophilicity.

201<smiles>[R]c1cc(OC)c(O)c2c1C(=O)c1c(C)ccnc1-2</smiles>

$\mathrm{R}=\mathrm{OH} 9$ $\mathrm{R}=\mathrm{H} \quad 10$<smiles>N=C(N)NCCC[C@H]1NCCc2c1[nH]c1cc(Br)ccc21</smiles>

13<smiles>C[n+]1ccc2cc3c(cc2c1Cc1ccc(O)cc1)OCO3</smiles>

11<smiles>COc1cc2c3c(c1O)-c1c(ccc(OC)c1OC)C[C@H]3NCC2</smiles>

12<smiles>[R]C(=O)NN(C)CCc1cc(Br)c(OCCCNC(=O)C2=NO[C@]3(CC(Br)=C(OC)C(Br)=CO3)[C@H]2O)c(Br)c1</smiles>

203 Figure 3. Published structures of natural products isolated from marine invertebrates and plants that are active against the malaria parasite. 
<smiles>c1ccc2c(c1)Nc1cc3cccnc3c3nccc-2c13</smiles>

16<smiles></smiles>

17<smiles></smiles>

18<smiles>CCC(/C=C/C(C)=O)CC(C)C[C@]1(CC)C[C@H](CC)[C@@H](CC(=O)O)OO1</smiles>

19<smiles>CCC(CC(C)C[C@]1(C)CC(CC)[C@@H](CC(=O)O)OO1)C(=O)O</smiles>

20<smiles>O=C1C=C(/C=C/c2ccccc2)O[C@H](C[C@H]2CC=CC(=O)O2)C1</smiles>

21
$\Delta^{7} 22$<smiles>COc1c(Br)cc(Br)c(CCNCCCN(C)C)c1Br</smiles>

23<smiles>COc1c(Br)cc(Br)c(CCN2C=[N+](C)CCC2)c1Br</smiles>

24

$$
\mathrm{HO}
$$

207 Figure 4. Published structures of natural products isolated from marine invertebrates 208 and plants that are active against the HAT parasite.

209<smiles>[R2]c1c(Br)cc(CC(=NO)C(=O)NCCCN(C)CCCCN(C)CCCNC(=O)C(Cc2cc(Br)c(OC)c(Br)c2)=NO)cc1CC(=NO)C(=O)NCCCN(C)CCCCN(C)CCCNC(=O)C(Cc1cc(Br)c(OC)c(Br)c1)NC</smiles><smiles>CNCCCCN(C)CCCNC(=O)/C(Cc1cc(Br)c(OC)c(Br)c1)=N/O</smiles>

29<smiles>CNCCCNC(=O)/C(Cc1cc(Br)c(OC)c(Br)c1)=N\O</smiles>

30

211 Figure 5. Published structures of natural products isolated from marine invertebrates 212 and plants that inhibit YOPE. 
214 Table 3. Physicochemical profiling of isolated natural products 9-30.

\begin{tabular}{ccccccc}
\hline & \multicolumn{6}{c}{ Physicochemical parameters $^{\mathrm{a}}$} \\
\cline { 2 - 7 } Compound & MW & Log P & Log D 5.5 & HBA & HBD & \%PSA \\
\hline Antimalarials & & & & & 2 & 23.5 \\
$\mathbf{9}$ & 257 & 2.67 & 2.67 & 5 & 1 & 18.1 \\
$\mathbf{1 0}$ & 241 & 2.33 & 2.33 & 4 & 1 & 10.2 \\
$\mathbf{1 1}$ & 294 & -1.38 & -1.38 & 3 & 2 & 12.4 \\
$\mathbf{1 2}$ & 327 & 1.80 & -0.62 & 5 & 5 & 20.6 \\
$\mathbf{1 3}$ & 350 & 1.87 & -3.65 & 4 & 3 & 19.5 \\
$\mathbf{1 4}$ & 790 & 3.14 & 3.14 & 8 & 3 & 15.8 \\
$\mathbf{1 5}$ & 747 & 3.74 & 0.65 & 8 & &
\end{tabular}

$\underline{\text { Antitrypanosomals }}$

$\begin{array}{lllllll}\mathbf{1 6} & 269 & 3.40 & 3.40 & 3 & 1 & 10.9 \\ \mathbf{1 7} & 283 & 2.98 & 2.98 & 4 & 0 & 16.1 \\ \mathbf{1 8} & 356 & 4.70 & 4.66 & 4 & 0 & 11.8 \\ \mathbf{1 9} & 368 & 5.29 & 4.37 & 5 & 1 & 11.2 \\ \mathbf{2 0} & 344 & 4.33 & 2.40 & 6 & 2 & 15.6 \\ \mathbf{2 1} & 312 & 3.33 & 3.33 & 3 & 0 & 11.9 \\ \mathbf{2 2} & 310 & 3.21 & 3.21 & 3 & 0 & 12.7 \\ \mathbf{2 3} & 473 & 4.05 & -1.64 & 3 & 1 & 4.88 \\ \mathbf{2 4} & 470 & 0.29 & 0.29 & 2 & 0 & 3.37 \\ \mathbf{2 5} & 898 & 0.62 & -0.09 & 11 & 4 & 21.2\end{array}$

YOPE actives

$\begin{array}{lllllll}\mathbf{2 6} & 914 & 2.25 & 0.90 & 10 & 5 & 15.4 \\ \mathbf{2 7} & 928 & 3.01 & 2.94 & 10 & 4 & 13.8 \\ \mathbf{2 8} & 522 & 1.51 & -2.65 & 6 & 3 & 13.0 \\ \mathbf{2 9} & 437 & 1.17 & 0.20 & 5 & 3 & 17.1 \\ \mathbf{3 0} & 928 & 3.82 & -3.10 & 9 & 4 & 11.4\end{array}$

$215{ }^{a}$ All in silico physicochemical properties were calculated using ChemAxon's Instant 216 JChem software version 3.0.4 (2009). 
218 As with many NP screening programs, the structure of each constituent in an extract or

219 fraction is generally not known prior to screening. The process described here addresses

220 Log P and MW so that the components adhere to contemporary concepts of lead- and

221 drug-likeness. It cannot, however, predefine structures. In some cases, although isolated

222 compounds may exist in lead- and drug-like space, they would not be considered for

223 further development, e.g. 16-18 which are reminiscent of DNA intercalators. NP

224 screening must therefore also be able to deliver two or three lead series in the same way

225 screening of pure compound libraries does so that a project team has options to pursue

226 if one series is chemically unattractive. Whilst singletons are not immediately

227 discounted, they can be considered too "high risk" and de-prioritized. This is

228 understandable given the cost to progress a lead through the drug discovery pipeline $229[47,63,64]$.

230 Fortunately, strategies can be easily implemented to deliver lead series that 231 provide insights into structure-activity relationships (SAR). One tactic employs the 232 compilation of a chemical knowledge base during the initial bioassay- or mass-directed 233 isolation process to facilitate isolation of analogues. Here, UV profiling in conjunction 234 with ${ }^{1} \mathrm{H}$ NMR spectroscopy permits other fractions derived from the same extract, or 235 extracts from closely related species in the same genus or family, to be scanned for 236 matching scaffolds or substructures. Subsequent scale-up chromatography can then 237 afford additional compounds of interest. This approach was used to isolate 238 pseudoceramines A 26, B 28 and spermatinamine 27 from the marine sponge 239 Pseudoceratina sp. in the YOPE project [59]. While compounds 26-28 accounted for 240 the bioactivity in the hit fractions, further large-scale extraction and isolation enabled 
241 the related bromotyrosine analogues, pseudoceramines C 29 and D 30 to be purified and screened.

Another approach enables a lead series to be expanded through simple

244 derivatization (e.g. methylation and acetylation reactions at a primary or secondary

245 amine, or hydroxyl group) on the active compound. Other functional groups like $\mathrm{Ar}-\mathrm{Br}$,

$246-\mathrm{COOH},-\mathrm{CHO}$, and $-\mathrm{NH}_{2}$ in the hit molecule lend themselves to Suzuki-Miyaura

247 couplings [65], reductive aminations, or the formation of amides/carbamates. By way of example, NPs 31-33 (Figure 6) were identified following screening against the

$\mu \mathrm{M}$, respectively. Subsequent methylation and acetylation of the most active compound, endiandrin A (31), using standard conditions yielded two more analogues for the series; diacetyl- $O$-endiandrin A (34) and dimethyl- $O$-endiandrin A (35).<smiles>[R20]c1ccc([C@@H]2[C@@H](C)[C@@H](C)[C@H]2c2ccc([R2])c(OC)c2)cc1OC</smiles>

$31 \mathrm{R}=\mathrm{H}$ $34 R=A C$ $35 \mathrm{R}=\mathrm{Me}$<smiles>COc1cc([C@H]2O[C@@H](c3ccc(O)c(OC)c3)[C@@H](C)[C@H]2C)ccc1O</smiles>

32

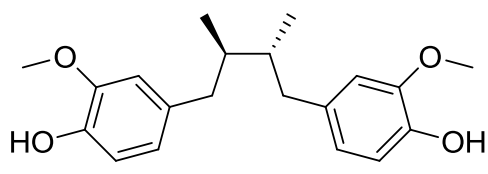

33

Figure 6. Chemical structures for endiandrin A 31, nectandrin B 32, (-)dihydroguaiaretic acid 33, diacetyl- $O$-endiandrin A 34, and dimethyl- $O$-endiandrin A 35.

Finally, there is no doubt that some NPs leads can be challenging to synthesize. Nevertheless, the arsenal of chemo- and stereoselective reactions now available to organic chemists versed in the art has resulted in some spectacular synthesis. The

261 remarkable story of discodermolide, a polyketide isolated from a Caribbean sponge 
262 having ten times the potency of paclitaxel $\left(\right.$ Taxol $\left.^{\circledR}\right) \mathbf{1}$ for tubulin polymerization and

263 microtubule stabilization, from initial synthetic efforts undertaken by various academic

264 groups to the synthesis of $60 \mathrm{~g}$ of pure compound by Novartis chemists [67-71] was

265 highlighted in a review by Koehn and Carter [72]. This is testimony to the increasing 266 power of modern synthetic methodologies. Another example is eribulin (Halaven ${ }^{\circledR}$ ) 37,

267 an antitumor drug based on a substructure found in the sponge NP, halichondrin B 36

268 (Figure 7), and manufactured by total synthesis to afford one of the more complex small 269 molecule drugs on the market to date. Indeed, as Koehn and Carter [72] comment, 270 "Success such as these make the compelling case that virtually no crucially important 271 compound is beyond the reach for clinical evaluation."

272

273

274

275

276

277

278

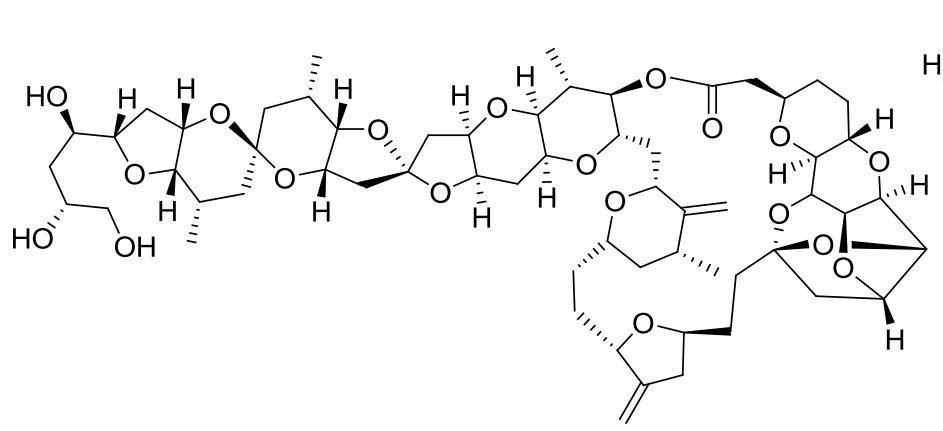

36

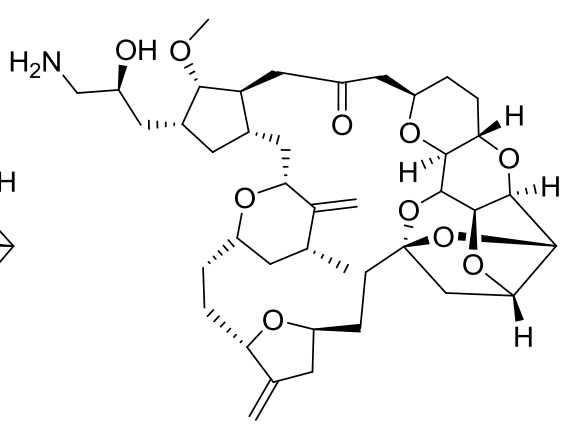

37

Figure 7. Chemical structures for halichondrin B $\mathbf{3 6}$ and eribulin $\mathbf{3 7 .}$

Fermentation is also an option for obtaining multi-gram quantities of the drug directly as is the case with the microbial NP, romidepsin, a histone deacetylase inhibitor [6]. Precursors en route to the actual drug may also be obtained from fermentation to deliver semi-synthetic drugs [73]. Trabectedin (Yondelis ${ }^{\circledR}$ ) 3 is a good example. The NP was originally isolated from the marine tunicate Ecteinascidia turbinata. Wild harvest of the tunicate could not deliver a sustainable source of the compound so the bacterium Pseudomonas fluorescens was used to afford the related safracin compounds [74]. A semi-synthetic procedure based on conversion of microbially produced cyanosafracin B was then developed to produce kilogram quantities of trabectedin [75]. Allowing 
283 microbials to produce scaffolds for further derivatization also facilitates the search for

284 more potent and selective compounds compared with the NP. The semisynthetic

285 cholesterol-lowering statin, simvastatin, for example, is more potent than the fungal NP,

286 lovastatin [73].

288 Guiding principle 2: Addressing access to genetic resources

The Convention on Biological Diversity

Prior to the CBD, the world's biodiversity was viewed as the common heritage

292 of mankind. The advent of the CBD has significantly and irrevocably altered

293 biodiscovery practices by providing a legal instrument that gives countries sovereignty

294 over their biodiversity and genetic resources and the right to control access [76]. In

295 return, signatories of the CBD have the responsibility to conserve and use their

296 biodiversity in a sustainable manner, and via Article 15, must facilitate access to genetic

297 resources and ensure equitable sharing of benefits arising from their use [101].

298 Whilst the CBD provided a clear policy and legal basis for source countries to

299 regulate access and benefit sharing (ABS), practical implementation of the third 300 objective (benefit sharing) and Article 15, in particular, has proven difficult. This was

301 due to several factors. First, there was the not insignificant matter of identifying a 302 negotiating party. Was it an individual, a community, government agency, or the 303 national government? Second, agreement had to be reached on a common 304 understanding of likely benefits such as the quantity and likelihood of monetary profits, 305 and the value of non-monetary benefits such as support for conservation and capacity 306 building. Third, the "value" of the players" respective contributions had to be 307 considered; custodianship and conservation of the resource from the provider versus 
308 innovation and investment costs from those developing genetic resources [77]. The

309 initial result in some instances was, at best, excessive negotiation and transaction costs

310 and, at worst, legal uncertainty - both disincentives to the industry investment required

311 to drive biodiscovery programs [26]. The CBD quite unintentionally spawned an era

312 where access to nature for biodiscovery had actually become more difficult. At the same

313 time, combinatorial chemistry was being pitched as a safer, more viable alternative for

314 the emerging HTS paradigm. It is little wonder then that the CBD failed to deliver the

315 anticipated bioprospecting bonanza to the developing world [78].

316 While implementation of international treaties like the CBD requires each

317 country to develop their own domestic laws and regulatory frameworks, the CBD

318 provided sufficient flexibility and policy guidance to enable individual institutions to

319 develop CBD compliant agreements ahead of schedule.

320

The Bonn Guidelines

322

In an effort to facilitate national legislation based on the CBD, the Bonn

323 Guidelines were drafted to provide helpful and specific, though voluntary, guidance on

324 measures related to implementation of ABS [103]. While some countries pursued

325 measures to promote biodiscovery and implement the Bonn Guidelines [79-81],[103]

326 the governments of many developing countries felt that their voluntary nature didn't go

327 far enough to combat biopiracy. Indeed, in 2004, the CBD and Bonn Guidelines were

328 themselves the recipient of the notorious Captain Hook Biopiracy Award, for "creating

329 the illusion that equitable benefit sharing is being addressed while facilitating

330 biopiracy..." [102]. After pressure from many developing countries in a range of

331 international forums, including the $2^{\text {nd }}$ World Summit on Sustainable Development and 
332 the $57^{\text {th }}$ meeting of the UN General Assembly, the CBD was handed a mandate to

333 develop a new international regime for access and benefit sharing [26],[104].

The resulting Nagoya Protocol is a legally binding protocol to the CBD [104].

As a consensus outcome following 6 years of intense, robust and often volatile negotiations over contentious issues and diametrically opposed views, the Nagoya Protocol is indeed a remarkable achievement. It was presented to (and adopted by) the $10^{\text {th }}$ Meeting of the CBD's Conference of the Parties in 2010 and, as at November 2011, had collected 64 signatories. It is expected to come into force in 2012.

The Nagoya Protocol is a major step forward in that it provides agreed

343 principles to deliver legal certainty and transparency for the entire value-chain of

344 biodiscovery, from original providers of the genetic resources, through to all stages in

345 the ensuing research and development, and the commercialisation process. Importantly,

346 the protocol includes provisions for clear demonstration of compliance, such as

347 certificates of compliance, and the introduction of checkpoints to transparently monitor

348 compliance. This is an important point as the potential for legal provenance and compliance with the Nagoya Protocol may become a criterion for patentability in the 350 future [82].

The challenge ahead is for parties to avoid developing onerous requirements that

352 increase transaction costs and undermine legal certainty. For example, certificates of

353 compliance must be practical and enforceable $[83,84]$ and checkpoints for on-going compliance should make use of existing regulatory procedures. Simple and accessible web-based databases and visualisation tools have been proposed as suitable methods for transparent compliance monitoring [85], and these hold great promise. 
In the case of developed, megadiverse countries like Australia, a recent analysis

358 of the existing and developing domestic regulatory framework for ABS has found that it

359 is already largely compliant with the Nagoya Protocol [86]. Moreover, government

360 authorities in Australia are extremely mindful of the need to avoid further regulatory

361 burden and instead look to existing mechanisms for passive check-points, such as

362 through funding bodies [87]. Taking a balanced approach that considers both the

363 position of the owner of genetic resources and that of industry will facilitate

364 biodiscovery. By addressing the legitimate concerns of developing nations with

365 megadiversity through the CBD, Bonn Guidelines and Nagoya Protocols, NP drug 366 discovery is now poised to re-emerge in a landscape of international and national legal

367 certainty.

368

369 Future perspective

370 The efficient screening and identification of small molecule modulators of

371 biological systems using HTS and high-content screening (HCS) will be employed for

372 many years to come. It is therefore paramount that NP researchers deliver new and

373 innovative approaches that dovetail with automated screening in order for NP drug 374 discovery to increase its current efficiency in identifying new drugs leads for 375 downstream development.

376 Innovation in delivering lead molecules is the key message here as many of the 377 technical challenges relating to isolation and structural elucidation of bioactive NPs 378 have been addressed [88,89]. Many NP PAINS, for instance, can be removed prior to 379 screening while prefractionation to afford a screen-friendly set is readily accomplished

380 by HPLC. Moreover, it is becoming increasingly commonplace that the structure of 381 many active component(s) in a fraction can be determined by LC-MS and NMR 
382 spectroscopy. This not only allows new and novel molecules to be distinguished from

383 previously identified compounds but also facilitates prioritization and allocation of

384 resources to isolation projects. The isolation of a pure compound in milligram quantities

385 can be achieved in a matter of hours using mass-directed isolation. Subsequent

386 structural elucidation by NMR spectroscopy is likewise completed in the same time

387 frame by skilled NP chemists. The entire procedure of going from an active fraction to a

388 defined molecule can be a matter of days rather than months [90].

389 Other improvements to NP drug discovery that borrow from efficiency gains first

390 employed in the HTS of combinatorial chemistry libraries are likewise possible. For

391 example, a drawback of preparing libraries in plate-based formats is the need to expose

392 an entire plate's contents to the potentially deleterious effects of the open laboratory

393 when only one fraction may be required for retesting. Dimethyl sulfoxide (DMSO) is

394 notoriously hygroscopic [91] and it is common knowledge among compound

395 management groups that the ingress of adventitious moisture can result in precipitation

396 of samples or an increased rate of degradation over successive freeze-thaw cycles

397 [92,93]. A modified procedure that addresses the issue of water uptake and limited

398 sample volume $(80 \mu \mathrm{L})$ per 384 well plate will go some way to further dovetailing NP

399 drug discovery with current paradigms. Microtubes, for example, permit cherry picking

400 of individual fractions and subsequent transfer to assay-ready plates via piercing of pre-

401 split septa $[94,95]$.

402 In terms of chemistry, innovative new leads may be acquired from previously

403 untapped sources of biota including a broader range of plant species, marine organisms

404 and microbes [96]. The marine environment is proving to be a particularly exciting

405 source of potential new leads [89,97]. 

these incremental improvements are coupled with a process that fundamentally aligns 408 itself with the now recognized principles of drug discovery. The optimization of extracts compliant with $\log \mathrm{P}$ that can then be fractionated to yield a screening set of

410 low chemical complexity per fraction while retaining chemical diversity space is just 411 one of potentially many ways this challenge can be addressed [42]. Coupling libraries

412 biased toward molecules with $\log \mathrm{P}$ values attractive for downstream development 413 together with mass-directed isolation (and incorporation of a MW filter) can

414 simultaneously address concerns about molecular obesity and the inherent slowness of 415 working with NPs $[13,98]$.

416 Although not directly relevant to discovering lead compounds for medicinal 417 chemistry, finding small-molecule probes that selectively interrogate physiological 418 processes is also an important application for NPs, and potentially a critical step in 419 showing that a particular site on a protein or process is "druggable" [99]. The 420 methodology described here can be modified to efficiently deliver NP probes (chemical 421 tools) of interest to the academic community for chemical biology or chemical genetics 422 projects. However, it is critical that the lessons learned from the early days of HTS are not forgotten even though probe compounds can explore chemistry space outside that typically used to define drugs and leads. If probe libraries are comprised of NP PAINS, non-lead-like molecules and aggregators, then the literature will be replete with artefact 426 data [5]. As Rishton puts it, "a good lead is a good tool is a good probe" while "a non427 lead is a non-tool is a non-probe" [100].

428 Finally, we perceive that policy and legal impediments surrounding biodiscovery have been largely settled in many countries and are heading in the right direction in 430 others. By way of example, legislation enacted by Australian Governments addresses 
431 historical issues associated with legal certainty, and compliance with international and

432 national laws pertaining to the use of genetic resources, and commercialization of 433 research [86].

434 In summary, the major impediments to discovery programs focused on NPs, i.e. 435 the issues of screening libraries suitable for downstream drug discovery and 436 development, and the policy problem of legal certainty and compliance, are being

437 resolved. The stage is now set for a renaissance of NPs to impact positively on drug 438 discovery and emerging interfacial sciences like chemical biology.

\section{Executive summary}

$441 \quad$ Setting the scene

- Slightly over 1,100 small molecule NCEs were introduced to the clinic from

443 January 1981 to December 2010. Of these, 34\% were NPs, or a semi-synthetic $444 \quad$ analogue.

445 - While this metric reflects the fact that NPs have historically been a fertile source of 446 new drugs for the pharmaceutical industry, this once popular approach has waned 447 considerably over the past two decades as a paradigm shift toward the HTS of mega 448 libraries comprised mainly of molecules with non-natural (synthetic) motifs has $449 \quad$ unfolded.

450 - This paradigm shift coincided, inter alia, with the introduction of the CBD, which 451 initially, albeit unintentionally, stymied access to biodiversity for NP drug discovery 452 programs on account of policy and legal hurdles.

453 - The classical NPs drug discovery approach employing bioassay-guided fractionation 454 has not been able to deliver compounds with physicochemical profiles considered 
essential for development into an orally administered drug in the same timelines as

456 the HTS of pure compound libraries.

457 Addressing physicochemical properties in natural product screening and improving the

458 speed that hits, leads and drugs are isolated.

459 - The physicochemical profiling of compound libraries that occurs in the

460 pharmaceutical industry has become an intrinsic part of the design and selection

$461 \quad$ process.

462 - One physicochemical descriptor has received particular attention; Log $\mathrm{P}$, the

463 partition coefficient of a compound between $n$-octanol and water, which is a

464 measure of a compound's lipophilicity.

465 - In one telling investigation, Leeson and Davis identified that the lipophilicity of

466 drugs, as measured by cLog $\mathrm{P}$, has remained constant over time suggesting that

467 departure from a narrow window can adversely affect the efficacy of a potential

468 therapeutic.

469 Next generation prefractionated extract libraries filtered on Log $P$

470 - NP workstreams that can align screening sets with lead- and drug-like

471 physicochemical profiles facilitate the downstream triage of biological and chemical

472 data.

473 - A NP drug discovery strategy based on Log P has proven its utility against three

474 anti-infective screens and holds much promise for timely isolation of NP leads at a

475 hitherto unachievable rate.

476 Addressing access to genetic resources

477 - Alongside demonstrated adaptation of NP screening sets for HTS, there has been 478 resolution of the legal and policy impediments to biodiscovery. The Nagoya 
480 benefit sharing.

481

482

483

484

485

486

487

488

489

490

491

492

493

494

495

496

497

498

499

500

501

502

503

504

505

506

507

508

509

510

511

512

513

514

515

516

517

518

519

520

- The scene is now set for a renaissance in biodiscovery by combining the molecular diversity inherent in nature with the discovery potential of HTS.

\section{References}

1. Gorse A-D. Diversity in Medicinal Chemistry Space. Curr. Top. Med. Chem., 6(1), 3-18 (2006).

2. Dobson CM. Chemical space and biology. Nature, 432(7019), 824-828 (2004).

3. Leeson PD, Springthorpe B. The influence of drug-like concepts on decision-making in medicinal chemistry. Nat. Rev. Drug Discovery, 6(11), 881-890 (2007). *A very good overview that outlines how drug-like concepts have caught the attention of the pharmaceutical and how they may be used to stymie innovation.

4. Baell JB, Holloway GA. New Substructure Filters for Removal of Pan Assay Interference Compounds (PAINS) from Screening Libraries and for Their Exclusion in Bioassays. J. Med. Chem., 53(7), 2719-2740 (2010). ${ }^{* *}$ The first article that appeared outlining how some chemical motifs do not actually make good leads because of their high hit rates across many different assays.

5. Baell JB. Observations on screening-based research and some concerning trends in the literature. Future Med. Chem., 2(10), 1529-1546 (2010).

6. Newman DJ, Cragg GM. Natural Products As Sources of New Drugs over the 30 Years from 1981 to 2010. J. Nat. Prod., 75, Web; 8 Feb (2012). ${ }^{* *}$ The latest in a series of reports by Newman and Cragg that showcases natural products as valuable leads for th epharmaceutical industry.

7. Grajal A. Biodiversity and the nation state: Regulating access to genetic resources limits biodiversity research in developing countries. Conserv. Biol., 13(1), 6-10 (1999).

8. Young TR. The Challenge of a New Regime: The Quest for Certainty in "Access to Genetic Resources and Benefit-Sharing". Asian Biotechnology and Development Review, 10(3), 113-136 (2008).

9. Macarron R. Critical review of the role of HTS in drug discovery. Drug Discov. Today, 11(7-8), 277-279 (2006).

10. Leeson PD, Davis AM. Time-related differences in the physical property profiles of oral drugs. J. Med. Chem., 47(25), 6338-6348 (2004). ${ }^{* *}$ Physicochemical profiling is undoubtedly important in modern drug discovery, but what makes this article differrent to to the rest is the way the issue was approached. 
11. Leeson PD, Davis AM, Steele J. Drug-like properties: guiding principles for design - or chemical prejudice? Drug Discov. Today: Technol., 1(3), 189-195 (2004).

12. Lipinski CA, Lombardo F, Dominy B, Feeney PJ. Experimental and computational approaches to estimate solubility and permeability in drug discovery and development settings. Adv. Drug Del. Rev., 23(1-3), 3-25 (1997). *The classic paper that has had a profound effect on the way in which drug discovery is prosecuted.

13. Hann MM. Molecular obesity, potency and other addictions in drug discovery. Med. Chem. Commun., 2(5), 349-355 (2011).

14. Macarron R, Luengo Jl. Yin and Yang in medicinal chemistry: what does drug-likeness mean? Future Med. Chem., 3(5), 505-507 (2011).

15. Sugano K, Kansy M, Artursson $P$ et al. Coexistence of passive and carrier-mediated processes in drug transport. Nat. Rev. Drug Discovery, 9(8), 597-614 (2010).

16. Teague SJ, Davis AM, Leeson PD, Oprea T. The Design of Leadlike Combinatorial Libraries. Angew. Chem. Int. Ed. Engl., 38(24), 3743-3747 (1999). ${ }^{*}$ The first paper describing the difference between leads as starting points and drugs as the end point.

17. Oprea TI, Bologa C, Olah MJ. Compound Selection for Virtual Screening. In: Virtual Screening in Drug Discovery. Alvarez, JC, Shoichet, B (Eds.) (Marcel Dekker Inc., 2004) 89-106.

18. Hann MM, Oprea TI. Pursuing the leadlikeness concept in pharmaceutical research. Curr. Opin. Chem. Biol., 8(3), 255-263 (2004).

19. Hansch C. Quantitative approach to biochemical structure-activity relationships. Acc. Chem. Res., 2(8), 232-239 (1969).

20. Tute MS. Principles and practice of Hansch analysis. Guide to structureactivity correlation for the medicinal chemist. In: Adv. Drug Res. Harper, NJ, Simmonds, AB (Eds.) (Academic, New York, USA, 1971) 1-77.

21. van de Waterbeemd $\mathrm{H}$, Smith DA, Beaumont K, Walker DK. Propertybased design: optimization of drug absorption and pharmacokinetics. J. Med. Chem., 44(9), 1313-1333 (2001).

22. Cronin MTD. The role of hydrophobicity in toxicity prediction. Curr. Comp. Aided Drug Des., 2(4), 405-413 (2006).

23. Ganesan A. The impact of natural products upon modern drug discovery. Curr. Opin. Chem. Biol., 12(3), 306-317 (2008).* One of the better reviews for natual products and their impact on contemporary drug discovery.

24. Williams J, Read C, Norton A et al. Biodiversity, Australia State of the Environment Report 2001 (Theme Report) (ed. Heritage, DotEa) (CSIRO Publishing, Melbourne, 2001).

25. Cordell GA, Colvard MD. Natural Products and Traditional Medicine: Turning on a Paradigm. J. Nat. Prod., 75, Web; 10 Jan (2012).

26. Evans-Illidge EA, Battershill CN. Marine Natural Products Discovery in Australia - from Reef to Royalty, and the Pursuit of Convention for Biological Diversity (CBD) compliance. Journal of Biolaw and Business, Special Supplement: Australia, 23-27 (2007).

27. ten Kate K, Laird SA. The Commercial Use of Biodiversity - Access to Genetic Resources and Benefit Sharing (Earthscan, London, 1999). 
28. Glowka L. A Guide to Designing Legal Frameworks to Determine Access to Genetic Resources (IUCN Switzerland and Germany, 1998).

29. McConnell K. The Biodiversity Convention - A Negotiating History (Kluwer Law International, London, 1996).

30. Gollin M. An Intellectual Property Rights Framework for Biodiversity Prospecting (WRI, Washington DC, 1993).

31. Bindseil KU, Jakupovic J, Wolf D, Lavayre J, Leboul J, van der Pyl D. Pure compound libraries; a new perspective for natural product based drug discovery. Drug Discov. Today, 6(16), 840-847 (2001).

32. Abel U, Koch C, Speitling M, Hansske FG. Modern methods to produce natural-product libraries. Curr. Opin. Chem. Biol., 6(4), 453-458 (2002).

33. Quinn RJ, Carroll AR, Pham NB et al. Developing a Drug-like Natural Product Library. J. Nat. Prod., 71(3), 464-468 (2008). ${ }^{*}$ One of the earliest articles to articulate the importance for natural products to undertake physicochemical profiling in line with current drug discovery programs.

34. Pereira DA, Williams JA. Origin and evolution of high throughput screening. Br. J. Pharmacol., 152(1), 53-61 (2007).

35. Quinn RJ. High-throughput screening in natural product drug discovery in Australia utilising Australia's biodiversity. Drug Dev. Res., 46(3-4), 250254 (1999).

36. Quinn RJ. QPRI's System for Screening of Natural Products. In: Bioassay Methods in Natural Product Research and Drug Development. Bohlin, L, Bruhn, JG (Eds.) (Kluwer Academic Publishers, Dordrecht, The Netherlands, 1999) 151-157.

37. Wagenaar MM. Pre-fractionated microbial samples - the second generation natural products library at Wyeth. Molecules, 13(6), 14061426 (2008).

38. Eldridge GR, Veroort HC, Lee CM et al. High-throughput method for the production and analysis of large natural product libraries for drug discovery. Anal. Chem., 74(16), 3963-3971 (2002). *The first paper to describe the preparation of prefractionated natural product HTS-ready libraries.

39. Appleton DR, Buss AD, Butler MS. A simple method for high-throughput extract prefractionation for biological screening. Chimia, 61(6), 327-331 (2007).

40. Tu Y, Jeffries $\mathrm{C}$, Ruan $\mathrm{H}$ et al. Automated High-Throughput System to Fractionate Plant Natural Products for Drug Discovery. J. Nat. Prod., 73(4), 751-754 (2010).

41. Bugni TS, Richards B, Bhoite L, Cimbora D, Harper MK, Ireland CM. Marine natural product libraries for high-throughput screening and rapid drug discovery. J. Nat. Prod., 71(6), 1095-1098 (2008).

42. Camp D, Davis RA, Campitelli M, Ebdon J, Quinn RJ. Drug-like Properties: Guiding Principles for the Design of Natural Product Libraries. J. Nat. Prod., 75(1), 72-85 (2012). *This paper makes a case for front-loading prefractionated natural product libraires with lead- and drug-like molecules prior to screening.

43. Johnson TA, Sohn J, Inman WD et al. Natural Product Libraries to Accelerate the High-Throughput Discovery of Therapeutic Leads. J. Nat. Prod., 74(12), 2545-2555 (2011). 
44. Shoichet BK. Screening in a spirit haunted world. Drug Discov. Today, 11, 607-615 (2006).

45. Thorne N, Auld DS, Inglese J. Apparent activity in high-throughput screening: origins of compound-dependent assay interference. Curr. Opin. Chem. Biol., 14, 315-324 (2010).

46. Macarron R, Banks MN, Bojanic D et al. Impact of high-throughput screening in biomedical research. Nat. Rev. Drug Discovery, 10(3), 188195 (2011).

47. Munos B. Lessons from 60 years of pharmaceutical innovation. Nat. Rev. Drug Discovery, 8(12), 959-968 (2009).

48. Lombardo F, Shalaeva MY, Tupper KA, Gao F, Abraham MH. ElogPoct: A tool for lipophilicity determination in drug discovery. J. Med. Chem., 43(15), 2922-2928 (2000).

49. Avery VM, Camp D, Carroll AR, Jenkins ID, Quinn RJ. The Identification of Bioactive Natural Products by High Throughput Screening (HTS). In: Comprehensive Natural Products II. Chemistry and Biology. Mander, LN, Lui, H-W (Eds.) (Elsevier, Oxford, UK, 2010) 177-203.

50. Hopkins AL, Groom CR, Alex A. Ligand efficiency: a useful metric for lead selection. Drug Discov. Today, 9(10), 430-431 (2004).

51. Buchanan MS, Davis RA, Duffy S, Avery VM, Quinn RJ. Antimalarial Benzylisoquinoline Alkaloid from the Rainforest Tree Doryphora sassafras. J. Nat. Prod., 72, 1541-1543 (2009).

52. Mueller D, Davis RA, Duffy S, Avery VM, Camp D, Quinn RJ. Antimalarial Activity of Azafluorenone Alkaloids from the Australian Tree Mitrephora diversifolia. J. Nat. Prod., 72(8), 1538-1540 (2009).

53. Davis RA, Duffy S, Avery VM, Camp D, Hooper JNA, Quinn RJ. (+)-7Bromotrypargine, an Antimalarial $\beta$-Carboline from the Australian Marine Sponge, Ancorina sp. Tetrahedron Lett., 51(4), 583-585 (2010).

54. Yang X, Davis RA, Buchanan MS et al. Antimalarial bromotyrosine derivatives from the Australian marine sponge Hyattella sp. J. Nat. Prod., 73(5), 985-987 (2010).

55. Feng $\mathrm{Y}$, Davis RA, Sykes ML et al. Antitrypanosomal pyridoacridine alkaloids from the Australian ascidian, Polysyncraton echinatum Tetrahedron Lett., 51(18), 2477-2479 (2010).

56. Feng Y, Davis RA, Sykes ML, Avery VM, Camp D, Quinn RJ. Pseudoceratinazole A: a novel bromotyrosine alkaloid from the Australian sponge Pseudoceratina sp. Tetrahedron Lett., 51(37), 48474850 (2010).

57. Feng Y, Davis RA, Sykes ML, Avery VM, Camp D, Quinn RJ. Antitrypanosomal cyclic polyketide peroxides from the Australian marine sponge Plakortis sp. J. Nat. Prod., 73(4), 716-719 (2010).

58. Davis RA, Sykes ML, Avery VM, Camp D, Quinn RJ. Convolutamines I and $\mathrm{J}$, antitrypanosomal alkaloids from the bryozoan Amathia tortusa. Bioorg. Med. Chem., 19(22), 6615-6619 (2011).

59. Yin S, Davis RA, Shelper $T$ et al. Pseudoceramines A-D, new antibacterial bromotyrosine alkaloids from the marine sponge Pseudoceratina sp. Org. Biomol. Chem., 9(19), 6755-6760 (2011).

60. Dictionary of Natural Products on DVD (Taylor and Francis Group / CRC Press, London, UK, 2011). 
682

683

684

685

686

687

688

689

690

691

692

693

694

695

696

697

698

699

700

701

702

703

704

705

706

707

708

709

710

711

712

713

714

715

716

61. Hillgren JM, Öberg CT, Elofsson M. Syntheses of pseudoceramines A-D and a new synthesis of spermatinamine, bromotyrosine natural products from marine sponges Org. Biomol. Chem., 10(6), 1246-1254 (2012).

62. Bhal SK, Kassam K, Peirson IG, Pearl GM. The rule of five revisited: Applying $\log D$ in place of $\log p$ in drug-likeness filters. Mol. Pharm., 4, 556-560 (2007).

63. DiMasi JA, Hansen RW, Grabowski HG. The price of innovation: new estimates of drug development costs. J. Health Econ., 22(2), 151-185 (2003).

64. DiMasi JA, Grabowski HG. The Cost of Biopharmaceutical R\&D: Is Biotech Different? Manage. Decis. Econ., 28(4-5), 469-479 (2007).

65. Davis RA, Fechner GA, Sykes ML et al. (-)-Dibromophakellin: An alpha 2B adrenoceptor agonist isolated from the Australian marine sponge, Acanthella costata. Bioorg. Med. Chem., 17(6), 2497-2500 (2009).

66. Davis RA, Carroll AR, Duffy $S$ et al. Endiandrin A, a Potent Glucocorticoid Receptor Binder Isolated from the Australian Plant Endiandra anthropophagorum. J. Nat. Prod., 70(7), 1118-1121 (2007).

67. Mickel SJ, Sedelmeier GH, Niederer D et al. Large-Scale Synthesis of the Anti-Cancer Marine Natural Product (+)-Discodermolide. Part 1: Synthetic Strategy and Preparation of a Common Precursor. Org. Proc. Res. Dev., 8(1), 92-100 (2004).

68. Mickel SJ, Sedelmeier GH, Niederer D et al. Large-Scale Synthesis of the Anti-Cancer Marine Natural Product (+)-Discodermolide. Part 2: Synthesis of Fragments C1-6 and C9-14. Org. Proc. Res. Dev., 8(1), 101-106 (2004).

69. Mickel SJ, Sedelmeier GH, Niederer D et al. Large-Scale Synthesis of the Anti-Cancer Marine Natural Product (+)-Discodermolide. Part 3: Synthesis of Fragment C15-21. Org. Proc. Res. Dev., 8(1), 107-112 (2004).

70. Mickel SJ, Sedelmeier GH, Niederer D et al. Large-Scale Synthesis of the Anti-Cancer Marine Natural Product (+)-Discodermolide. Part 4: Preparation of Fragment C7-24. Org. Proc. Res. Dev., 8(1), 113-121 (2004).

71. Mickel SJ, Niederer D, Daeffler R et al. Large-Scale Synthesis of the Anti-Cancer Marine Natural Product (+)-Discodermolide. Part 5: Linkage of Fragments C1-6 and C7-24 and Finale. Org. Proc. Res. Dev., 8(1), 122-130 (2004).

72. Koehn FE, Carter GT. Nat. Rev. Drug Discovery, 4(3), 206-220 (2005).

73. Kennedy J. Mutasynthesis, chemobiosynthesis, and back to semisynthesis: combining synthetic chemistry and biosynthetic engineering for diversifying natural products. Nat. Prod. Rep., 25(1), 25-34 (2008).

74. Ikeda $\mathrm{Y}$, Idemoto $\mathrm{H}$, Hirayama $\mathrm{F}$ et al. Safracins, new antitumor antibiotics. I. Producing organism, fermentation and isolation. J. Antibiot., 36(10), 1279-1283 (1983).

75. Cuevas C, Pérez M, Martín MJ et al. Synthesis of Ecteinascidin ET-743 and Phthalascidin Pt-650 from Cyanosafracin B. Org. Lett., 2(16), 25452548 (2000).

76. Evans-Illidge E. Natural Ways - learning from Nature's 4.5 billion year biotechnology project. Australasian Science, 67, 36-39 (2004). 
77. Camp D, Quinn RJ. Biodiscovery for natural product pharmaceuticals: an Australian experience. Journal of Biolaw and Business, Special Supplement: Australia, 39-43 (2007).

78. Dalton R. Bioprospects less than golden. Nature, 429(6992), 598-600 (2004).

79. Carrizosa S, Brush SB, Wright BD, McGuire PE. Accessing Biodiversity and Sharing the Benefits: Lessons from Implementing the Convention on Biological Diversity (IUCN, Gland, Switzerland and Cambridge, UK, 2004).

80. Benavidez (II) P. The Challenges in the Implementation of the Philippine ABS Regulations: Monitoring and Enforcement of Bioprospecting Activities. In: International Expert Workshop on Access to Genetic Resources and Benefit Sharing, 24 - 27 October, 2004. Bellot-Rojas, M, Bernier, S (Ed.^(Eds) (Record of discussion available at www.canmexworkshop.com, Cuernavaca, Mexico, 2005)

81. Lettington RJL. National Access Laws, Continuing Monitoring, and Enforcement Issues. In: International Expert Workshop on Access to Genetic Resources and Benefit Sharing, 24 - 27 October, 2004. BellotRojas, M, Bernier, S (Ed.^(Eds) (Record of discussion available at www.canmexworkshop.com, Cuernavaca, Mexico, 2005)

82. Buck M, Hamilton C. The Nagoya Protocol on Access to Genetic Resources and the Fair and Equitable Sharing of Benefits Arising from their Utilization to the Convention on Biological Diversity. RECIEL, 20(1), 47-61 (2011).

83. Young TR. A Simple Solution: Using Certificates of Legal Provenance as a Workable Component of a Functional Regime on ABS. In: International Expert Workshop on Access to Genetic Resources and Benefit Sharing, 24 - 27 October, 2004. Bellot-Rojas, M, Bernier, S (Ed.^(Eds) (Record of discussion available at www.canmexworkshop.com, Cuernavaca, Mexico, 2005)

84. Fernandez JC. Elements for the Design of a Certificate of Legal Provenance. In: International Expert Workshop on Access to Genetic Resources and Benefit Sharing, 24 - 27 October, 2004. Bellot-Rojas, M, Bernier, S (Ed.^(Eds) (Record of discussion available at www.canmexworkshop.com, Cuernavaca, Mexico, 2005)

85. Mukherjee J, Llewellyn LE, Evans-Illidge EA. A tropical marine microbial natural products geobibliography as an example of desktop exploration of current research using web visualisation tools. Mar. Drugs, 6(4), 550577 (2008).

86. Burton G. Australia - Staying ahead of the game (Abstract only). In: 2nd National Biodiscovery Forum, 4 - 5 August, 2011. (Ed.^(Eds) (Adelaide, Australia, 2011)

87. Philips B. New incentives for conserving biodiversity (Abstract only). In: 2nd National Biodiscovery Forum, 4 - 5 August, 2011. (Ed.^(Eds) (Adelaide, Australia, 2011)

88. Harrigan GG, Goetz GH. Chemical and Biological Integrity in Natural Products Screening. Comb. Chem. High Throughput Screen., 8(6), 529534 (2005). 
89. Harvey AL. Natural products as a screening resource. Curr. Opin. Chem. Biol., 11(5), 480-484 (2007).

90. Harvey AL. Medicines from nature: are natural products still relevant to drug discovery? Trends Pharmacol. Sci., 20(5), 196-198 (1999).

91. Catalan J, Diaz C, Garcia-Blanco F. Characterization of Binary Solvent Mixtures of DMSO with Water and Other Cosolvents. J. Org. Chem., 66(17), 5846-5852 (2001).

92. Zitha-Bovens E, Maas P, Wife D et al. COMDECOM: Predicting the Lifetime of Screening Compounds in DMSO Solution. J. Biomol. Screening, 14(5), 557-565 (2009).

93. Kozikowski BA, Burt TM, Tirey DA et al. The Effect of Freeze/Thaw Cycles on the Stability of Compounds in DMSO. J. Biomol. Screening, 8(2), 210-215 (2003).

94. Camp D, Avery VM, Street I, Quinn RJ. Progress towards establishing an open access molecular screening capability in the Australasian region. ACS Chem. Biol., 2(12), 764-767 (2007).

95. Hofmann A, Wang CK, Osman A, Camp D. Merging structural biology with chemical biology: Structural Chemistry at Eskitis. Struct. Chem., 21(5), 1117-1129 (2010).

96. Harvey AL. Strategies for discovering drugs from previously unexplored natural products. Drug Discov. Today, 5(7), 294-300 (2000).

97. Sashidhara KV, White KN, Crews P. A Selective Account of Effective Paradigms and Significant Outcomes in the Discovery of Inspirational Marine Natural Products. J. Nat. Prod., 72(3), 588-603 (2009).

98. Harvey AL. Natural products in drug discovery. Drug Discov. Today, 13(19-20), 894-901 (2008).

99. Kritzer JA. Beyond discovery: probes that see, grab and poke. Nat. Chem. Biol., 6(12), 868-870 (2010).

100. Rishton GM. Molecular diversity in the context of leadlikeness: compound properties that enable effective biochemical screening. Curr. Opin. Chem. Biol., 12(3), 340-351 (2008). *This article reminds us that screening libraires for chemical biology must still conform to acceptable physicochemical profiles and structural motifs.

\section{Websites}

101. The convention on biological diversity 1992. http://www.cbd.int

102. Captain Hook Awards 2004. http://www.captainhookawards.org

103. The Bonn guidelines on access to genetic resources and fair and equitable sharing of the benefits arising out of their utilisation 2002. http://www.biodiv.org/doc/publications/cbd-bonn-gdls-en.pdf 
807 104. The Nagoya protocol on access to genetic resources and the fair and equitable 808 sharing of benefits arising from their utilization to the convention on biological 809 diversity. 2011. http://www.cbd.int/abs/text/

810 